\title{
Decompressive Hemicraniectomy in Acute Neurological Diseases
}

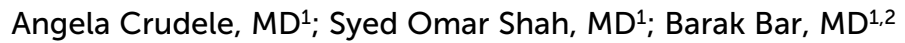 \\ Department of Neurology, Thomas Jefferson University, Philadelphia, PA, \\ Department of Neurological Surgery, Thomas Jefferson University, Philadelphia, PA,
}

\begin{abstract}
Increased intracranial pressure (ICP) secondary to severe brain injury is common. Increased ICP is commonly encountered in malignant middle cerebral artery ischemic stroke, traumatic brain injury, subarachnoid hemorrhage, and intracerebral hemorrhage. Multiple interventions - both medical and surgical - exist to manage increased ICP. Medical management is used as first-line therapy; however it is not always effective and is associated with significant risks. Decompressive hemicraniectomy is a surgical option to reduce ICP, increase cerebral compliance, and increase cerebral blood perfusion when medical management becomes insufficient. The purpose of this review is to provide an up-to-date summary of the use of decompressive hemicraniectomy for the management of refractory elevated ICP in malignant middle cerebral artery ischemic stroke, traumatic brain injury, subarachnoid hemorrhage, and intracerebral hemorrhage.
\end{abstract}

\section{KEYWORDS}

Decompressive Hemicraniectomy, Intracerebral Hemorrhage, Malignant MCA Stroke, Traumatic Brain Injury, Aneurysmal Subarachnoid Hemorrhage, Intracranial Pressure, Herniation

\section{INTRODUCTION}

Increased intracranial pressure (ICP) secondary to cerebral edema is common in acute neurological disorders. Severe edema can be seen in malignant middle cerebral artery (MCA) ischemic stroke, traumatic brain injury (TBI), subarachnoid hemorrhage (SAH), and intracerebral hemorrhage (ICH). Increased ICP can lead to life-threatening herniation syndromes and is a common cause of death when left untreated.

Decompressive hemicraniectomy (DHC) is a surgical option to reduce ICP, increase cerebral compliance, and increase cerebral blood perfusion when medical management becomes insufficient. By removing the skull, the brain is allowed to expand, thereby normalizing ICP and reducing compression and/or midline shift. By reducing ICP, cerebral perfusion pressure and blood flow are restored.

This article will summarize current medical literature regarding DHC in intracerebral hemorrhages, subarachnoid hemorrhage, malignant MCA stroke and traumatic brain injury.

\section{DHC IN THE SETTING OF INTRACEREBRAL HEMORRHAGE}

Current guidelines for the management of spontaneous ICH developed from the American Heart Association and American Stroke Association (AHA/ASA) recommend initial medical therapy for elevated ICP (external ventricular drainage [EVD]). ${ }^{1}$ The guidelines also address surgical management, but not for treatment of refractory elevated ICP.

There are currently no large randomized controlled trials regarding the use of DHC in $\mathrm{ICH}$. There have only been a few case/control and case series regarding $\mathrm{DHC}$ for management of refractory ICP in $\mathrm{ICH}$, and these studies are divided between $\mathrm{DHC}$ alone versus a hematoma evacuation alongside with $\mathrm{DHC} .^{2-9}$ Table 1 provides a summary of the key studies that have been published thus far.

\section{DHC WITHOUT HEMATOMA EVACUATION}

We were able to find two relevant studies in which DHC was done without evacuation of the hematoma. The largest study conducted by Ramnarayan et al. ${ }^{4}$ evaluated 23 patients with primary putaminal hemorrhage. Only seven patients had a Glasgow Comas Scale (GCS) less than 8 , while more than half had a GCS of 9-12. Seven patients had an $\mathrm{ICH}$ volume of greater than $60 \mathrm{cc}$, while 13 had a volume between 30-60 cc. The majority of patients had surgery performed within 6 hours of presentation, but no details regarding exact timing were provided. Mortality rate was low in this case series $(13 \%)$, but this finding may be partly explained by the low severity of illness with a relatively high GCS and small hematoma volumes. ICH score was not reported which would have allowed for better comparison with other studies.

Fung et al. ${ }^{8}$ performed a case-control study of 12 patients. These patients had a larger median hematoma volume of 61 cc compared to Ramnarayan et al. ${ }^{4}$ Median time to DHC was within 12 hours with a mortality rate of $25 \%$ in the $\mathrm{DHC}$ group while the controls had a $53 \%$ mortality rate. Mortality was higher in the control group with hemorrhages greater than $60 \mathrm{cc}$ as compared to the DHC group.

\section{DHC WITH HEMATOMA EVACUATION}

The oldest and largest reported series of patients with hematoma evacuation along with $\mathrm{DHC}$ is a 73 patient casecontrol series by Dierssen et al. ${ }^{9}$ in 1983. 


\begin{tabular}{|c|c|c|c|c|c|c|c|c|c|c|c|}
\hline Authors & $\begin{array}{l}\text { Study } \\
\text { Design }\end{array}$ & $\begin{array}{l}\text { No. of } \\
\text { Cases }\end{array}$ & $\begin{array}{l}\text { Age } \\
\text { (years) }\end{array}$ & $\begin{array}{l}\text { Admission } \\
\text { GCS }\end{array}$ & $\begin{array}{l}\text { ICH } \\
\text { Volume } \\
\text { (cc) }\end{array}$ & $\begin{array}{l}\text { Percentage } \\
\text { with IVH }\end{array}$ & $\begin{array}{l}\text { ICH } \\
\text { Score }\end{array}$ & $\begin{array}{l}\text { Time } \\
\text { to DHC } \\
\text { (hours) }\end{array}$ & Mortality & $\begin{array}{l}\text { Good } \\
\text { Outcome }\end{array}$ & $\begin{array}{l}\text { Follow-up } \\
\text { Duration }\end{array}$ \\
\hline \multicolumn{12}{|c|}{ Decompressive Craniectomy WITH clot evacuation } \\
\hline $\begin{array}{l}\text { Dierssen et } \\
\text { al, } 1983\end{array}$ & $\begin{array}{l}\text { Case- } \\
\text { Control }\end{array}$ & 73 & $\begin{array}{l}52 \\
\text { (mean) }\end{array}$ & $\begin{array}{l}43 \\
\text { stuporous to } \\
\text { deep coma }\end{array}$ & unknown & $33 \%$ & unknown & unknown & $33 \%$ & $\begin{array}{l}45 \% \text { (no } \\
\text { deficit } \\
\text { to minor } \\
\text { deficit only }\end{array}$ & 2 years \\
\hline $\begin{array}{l}\text { Murthy et al. } \\
2005\end{array}$ & Case Series & 12 & $\begin{array}{l}49.8 \\
\text { (mean) }\end{array}$ & 7 (median) & $\begin{array}{l}71 \\
\text { (mean) }\end{array}$ & $92 \%$ & $\begin{array}{l}3 \\
\text { (median) }\end{array}$ & $\begin{array}{l}10.7 \\
\text { (mean) }\end{array}$ & $8 \%$ & $\begin{array}{l}55 \% \text { (mRS } \\
0-3)\end{array}$ & 17 months \\
\hline $\begin{array}{l}\text { Kim et al., } \\
2009\end{array}$ & Case Series & 24 & $\begin{array}{l}56.2 \\
\text { (mean) }\end{array}$ & $\begin{array}{l}19 \text { with GCS } \\
<8\end{array}$ & unknown & unknown & unknown & $\begin{array}{l}8.3 \\
\text { (mean) }\end{array}$ & $25 \%$ & $\begin{array}{l}50 \% \text { (GOS } \\
4-5)\end{array}$ & 6 months \\
\hline $\begin{array}{l}\text { Ma et al., } \\
2010\end{array}$ & $\begin{array}{l}\text { Case- } \\
\text { Control }\end{array}$ & 38 & $\begin{array}{l}43 \\
\text { (mean) }\end{array}$ & $\begin{array}{l}11.0 \\
\text { (mean) }\end{array}$ & $\begin{array}{l}58 \\
\text { (mean) }\end{array}$ & $74 \%$ & $\begin{array}{l}3 \\
\text { (mean) }\end{array}$ & 22 (mean) & $32 \%$ & $\begin{array}{l}55 \% \text { (GOS } \\
3-5)\end{array}$ & 6 months \\
\hline $\begin{array}{l}\text { Takeuchi et } \\
\text { al., } 2013\end{array}$ & Case Series & 21 & $\begin{array}{l}57.1 \\
\text { (mean) }\end{array}$ & $\begin{array}{l}6.9 \\
\text { (mean) }\end{array}$ & $\begin{array}{l}74 \\
\text { (mean) }\end{array}$ & $52 \%$ & $\begin{array}{l}3 \\
\text { (median) }\end{array}$ & $\begin{array}{l}\text { Within } 24 \\
\text { hours }\end{array}$ & $17 \%$ & $\begin{array}{l}25 \% \text { (GOS } \\
4-5)\end{array}$ & 135 days \\
\hline \multicolumn{12}{|c|}{ Decompressive Craniectomy WITHOUT clot evacuation } \\
\hline $\begin{array}{l}\text { Ramnarayan } \\
\text { et al., } 2009\end{array}$ & Case Series & 23 & $31-68$ & $\begin{array}{l}7 \text { with GCS } \\
3-8\end{array}$ & $\begin{array}{l}\text { More than } \\
60 \text { in } 7\end{array}$ & $26 \%$ & unknown & unknown & $13 \%$ & $\begin{array}{l}56 \% \text { (GOS } \\
5 \text { ) }\end{array}$ & 1 month \\
\hline $\begin{array}{l}\text { Fung et al., } \\
2012\end{array}$ & $\begin{array}{l}\text { Case- } \\
\text { Control }\end{array}$ & 12 & $\begin{array}{l}48 \\
\text { (median) }\end{array}$ & $\begin{array}{l}8 \\
\text { (median) }\end{array}$ & $\begin{array}{l}61 \\
\text { (median) }\end{array}$ & unknown & unknown & $\begin{array}{l}12 \\
\text { (median) }\end{array}$ & $25 \%$ & $\begin{array}{l}75 \% \text { (mRS } \\
0-4)\end{array}$ & 6 months \\
\hline
\end{tabular}

GCS was not directly reported on admission, but 43 (59\%) patients presented with a neurological exam of stupor to deep coma. Despite having a poor initial presentation, the long-term functional outcome was good in nearly half of the survivors and a statistically significant improvement in mortality was found in the DHC group. Murthy et al..$^{5}$ published a 12 patient cases series in which the majority of the patients $(92 \%)$ survived to follow-up at 17 months, and good functional outcome was achieved in 55\% of patients (mRS 0-3). Good functional outcome would have increased to $67 \%$ if it was defined as a mRS of 0-4. One methodological weakness in this study is possible selection bias as $92 \%$ of the patients had right hemisphere pathology.

A larger case series was published by Kim et al. ${ }^{7}$ including 24 patients, 19 (79\%) of whom had a GCS less than 8. Good functional outcome was defined as a GOS of 4-5 and was present in half the patients at 6 months. Most of the patients had poor neurological exams, but the authors did not provide enough information to determine the utility of DHC. Also, indications for surgery in this study (GCS <8) may have caused delays for patients that would have benefited from earlier decompression.

Ma et al. ${ }^{6}$ performed a case-control study of 38 patients. Controls were patients who received a hematoma evacuation alone. In unadjusted analysis, there was a $32 \%$ mortality rate in the DHC group compared to $43 \%$ in the control group $(p=0.26)$. There were significantly more patients with herniation, patients with intraventricular hemorrhage (IVH), and patients with a higher $\mathrm{ICH}$ score in the DHC group than the control group. The patients' ICH score, hematoma volumes, and admission GCS may have played a role in the higher mortality rates than other studies in our review. When adjusted for these variables, the odds ratio for 30 -day mortality was 0.12 (95\% $\mathrm{Cl} 0.02-0.64, \mathrm{p}=0.01$ ), and an adjusted odds ratio for good outcome (GOS 3-5) of $23.23(95 \% \mathrm{Cl} 2.13-252.86, p=0.01)$.
The most recent study was conducted by Takeuchi et al. ${ }^{2}$ The median ICH score was 3, and all patients were taken for surgery within 24 hours of presentation. Patients had lower GCS scores, higher $\mathrm{ICH}$ volumes, and longer delay prior to surgery in comparison to other studies reviewed, which may explain the worse outcomes.

\section{CONCLUSIONS}

Bearing in mind the differences in methodology between all 7 studies, there was an overall combined mortality of $26 \%$. It is fair to conclude that DHC done alone or combined with hematoma evacuation appears to be safe. Patients in both populations demonstrated that this surgical technique may reduce mortality, as well as improve functional outcome, especially in those who have large hematoma volume, low GCS score, and high $\mathrm{ICH}$ score.

We recommend that patients with refractory ICP elevation in the setting of $\mathrm{ICH}$ 
Figure 2 .

\begin{tabular}{|l|l|l|l|l|l|l|}
\hline Authors & Study Design & $\begin{array}{l}\text { Total Study } \\
\text { Population }\end{array}$ & Age (years) & Clinical Presentation & Fisher Grade \\
Coiling
\end{tabular}

should undergo DHC with or without hematoma evacuation depending on individual characteristics. Patients that seem to benefit the most are those with poor neurological exams and large hematoma volumes. If a decision is made to proceed with $\mathrm{DHC}$, it should be performed in a timely manner as delay is associated with diminishing benefit.

\section{DHC IN THE SETTING OF ANEURYSMAL SUBARACHNOID HEMORRHAGE}

DHC has been performed for the management of refractory elevated ICP in patients suffering from aneurysmal subarachnoid hemorrhage (SAH). The current literature consists of single institution case series and a single case control study. Table 2 provides a summary of the key studies that have been published thus far. The largest study done by Dorfer et al. ${ }^{10}$ stratified patients into 4 different groups for their retrospective analysis. Group 1 consisted of patients undergoing aneurysm clipping and $\mathrm{DHC}$ during the initial procedure (i.e., primary DHC). Group 2 consisted of patients undergoing $\mathrm{DHC}$ who had endovascular treatment of their ruptured aneurysm and developed intractable intracranial hypertension immediately or in a delayed fashion. Group 3 consisted of patients who had DHC done after initial clipping of aneurysm but in a delayed fashion. Group 4 consisted of patients in group 1 who required repeat surgery to enlarge the primary $\mathrm{DHC}$. The authors found no significant difference in neurological outcome based on the group the patient was assigned. Interestingly, the authors did not find that timing of DHC influenced functional outcome. The main finding of their study was that etiology of intractable ICP influenced functional outcome. Patients undergoing $\mathrm{DHC}$ due to intractable ICP elevation secondary to a hematoma had improved functional outcome $(p=0.038)$ compared to patients undergoing DHC due to cerebral edema secondary to ischemic infarction. The weakness of the study is the lack of a comparison group and its retrospective design.

In contrast, Buschmann et al. ${ }^{11}$ also grouped patients based on indication for $D H C$ and showed that timing of DHC could potentially be a factor affecting long-term functional outcome. Patients in group 1 had primary DHC; group 2 were patients who developed intractable ICP (>20 $\mathrm{mmHg}$ ) and space occupying epidural, subdural, or intracerebral hematoma after aneurysm surgery (secondary DHC due to hematoma); group 3 consisted of patients who developed cerebral edema and intractable ICP without infarctions (secondary DHC without infarctions); and group 4 had elevated ICP and infarctions (secondary DHC with infarctions). Notably the majority of the patients in their study were in group 1 (55\%). Patients who recovered with good functional outcome (GOS 4 and 5) were treated earlier by secondary DHC (within $3.6 \pm 1.6$ days after $\mathrm{SAH}$ ) than those who died or survived with severe or moderate disability (GOS 1-3) who were treated later (within $5.9 \pm 5.5$ days $[p=0.12]$ ). Also in this study, the outcome of the patients differed according to the indication for DHC with $83.3 \%$ of patients in group 3 (secondary DHC without infarctions) having a good functional outcome. 


\begin{tabular}{|c|c|c|c|c|}
\hline $\begin{array}{l}\text { Outcome } \\
\text { Assessment }\end{array}$ & $\begin{array}{l}\text { Follow-up } \\
\text { Duration }\end{array}$ & $\begin{array}{l}\text { Timing of DHC after } \\
\text { SAH }\end{array}$ & Good Outcome & Comments \\
\hline $\mathrm{mRS}$ & 14.9-48.2 months & $\begin{array}{l}\text { Varied according to } \\
\text { indication }\end{array}$ & $28 \%$ (mRS 0-3) & $\begin{array}{l}\text { Subgroup of patients with } \mathrm{DHC} \text { due to hematoma formation had } \\
\text { improved outcome }(\mathrm{P}=0.038) \text { compared to patients with } \mathrm{DHC} \text { due } \\
\text { to cerebral edema secondary to ischemic infarction }\end{array}$ \\
\hline GOS) & 12 months & $\begin{array}{l}\text { Varied according to } \\
\text { indication }\end{array}$ & $53 \%$ (GOS 4-5) & $\begin{array}{l}\text { Subgroup of patients with DHC for treatment of cerebral edema } \\
\text { without infarction had } 83.3 \% \text { good functional outcome }\end{array}$ \\
\hline $\begin{array}{l}\text { mRS, GOS, } \\
E Q-5 d\end{array}$ & 12 months & 11.4 hours & $33 \%$ (mRS 0-3) & $\begin{array}{l}\text { Poor-grade aSAH patients with associated ICH and evidence of } \\
\text { focal mass effect treated with DHC did not have improved quality } \\
\text { of life compared to a similar group of patients treated conserva- } \\
\text { tively. }\end{array}$ \\
\hline $\mathrm{mRS}$ & $\begin{array}{l}\text { 39-1175 days, } \\
\text { median } 450\end{array}$ & $\begin{array}{l}2 \text { days (median), } 3.2 \\
\text { days (mean) }\end{array}$ & $44 \%$ (mRS 0-3) & $\begin{array}{l}\text { Early DHC was associated with better outcome: } 6 / 8 \text { patients }(75 \%) \\
\text { had good mRS outcomes compared with } 1 / 8 \text { patients in whom the } \\
\text { decompression was performed after } 48 \text { hours }(p<0.01) \text {. }\end{array}$ \\
\hline $\mathrm{mRS}$ & 6 months & $\begin{array}{l}7.7 \text { hours (primary), } \\
93.6 \text { hours } \\
\text { (secondary) }\end{array}$ & $26 \%$ (mRS 0-3) & $\begin{array}{l}\text { The outcome was comparable regardless of the underlying } \\
\text { etiology leading to DHC being performed. }\end{array}$ \\
\hline mGOS & 12 months & NA & $62 \%$ (excellent/good) & $\begin{array}{l}\text { Only included patients with MCA aneurysm associated with hema- } \\
\text { toma volume greater than } 25 \mathrm{~mL} \text {. }\end{array}$ \\
\hline
\end{tabular}

However, there were only 6 patients in this group. Overall, $53 \%$ of the patients had a good functional outcome (GOS 4-5) at 1 year which is impressive given that $82 \%$ of the patients presented with a Hunt and Hess grade IV-V SAH.

Nonetheless, the study by D'Ambrosio et al. ${ }^{12}$ came to a different conclusion. In this study of poor-grade SAH patients presenting with focal ICH necessitating DHC, quality of life (QoL) was assessed in addition to functional outcome. Notably the patients all had Hunt and Hess grade IV-V SAH and clinical signs of brainstem compression. Patients who underwent $\mathrm{DHC}$ did not have improved QoL or functional outcome compared to a similar group of patients treated conservatively. A methodological weakness is that the control group used had smaller hematoma volume, less midline shift, and higher GCS. Furthermore, although the average time to hemicraniectomy for the group as a whole was only $11.4( \pm 4.3)$ hours, half the patients had DHC performed greater than 24 hours after onset of clinical signs of brainstem compression. However, the authors did not find a statistically significant difference comparing the early hemicraniectomy group to the control group. Given the small sample size, the subgroup analysis is not powered to detect a statistically significant difference. Despite the negative findings of this study, $33 \%$ of patients in the DHC group had a good functional outcome at one year.

A similar study was conducted by Smith et al., ${ }^{13}$ also in a population of poorgrade $\mathrm{SAH}$ patients presenting with a focal ICH (sylvian fissure hematoma greater than $25 \mathrm{~mL}$ ipsilateral to an MCA aneurysm). However, unlike the study done by D'Ambrosio et al., ${ }^{12}$ the patients in this study all had a prophylactic DHC which was planned from the outset of the aneurysm clipping operation. This earlier time frame for the performance of the DHC may explain the significantly different results which showed that $62 \%$ of the patients had good functional outcome at one year. Unfortunately the authors do not report on the actual timing of the $\mathrm{DHC}$ in relation to onset of $\mathrm{SAH}$. In this study, DHC led to significant and sustained decrease in elevated ICP and the procedure added only 20-25 minutes to the original operation.
In contrast to the two previous studies, Schirmer et al. ${ }^{14}$ evaluated patients presenting with $\mathrm{SAH}$ with small to no $\mathrm{ICH}$. Notably, in this small study half of the patients had their aneurysm treated via endovascular coiling. This study also lends support to the idea that early DHC may be more beneficial than delayed DHC. The authors noted that DHC performed within the first 48 hours after $\mathrm{SAH}$ had a beneficial effect on outcome: $75 \%$ of the patients who underwent early DHC fared better at long-term followup (mRS $0-3$ ) compared to $12.5 \%$ of patients in whom DHC was performed after 48 hours $(p<0.01)$. The strength of this study is that herniated brain volume was assessed, however the authors do not describe in detail what is meant by maximal medical management which was an inclusion criteria.

Lastly, Guresir et al. ${ }^{15}$ evaluated the outcome of patients undergoing primary or secondary $\mathrm{DHC}$ for management of refractory elevated ICH stratified according to the different underlying pathologies in order to determine predictors to help guide treatment. Patients were stratified as follows: group 1 (primary DHC) had 


\begin{tabular}{|c|c|c|c|c|c|}
\hline \multirow[t]{2}{*}{ Authors } & \multirow[t]{2}{*}{$\begin{array}{l}\text { No. of } \\
\text { Cases }\end{array}$} & \multirow[t]{2}{*}{$\begin{array}{l}\text { Ages } \\
\text { Represented }\end{array}$} & \multirow[t]{2}{*}{$\begin{array}{l}\text { Hours to } \\
\text { Surgery }\end{array}$} & \multicolumn{2}{|c|}{$\begin{array}{l}\text { Outcomes: Surgery versus } \\
\text { Medical }\end{array}$} \\
\hline & & & & Mortality & $\mathrm{mRS}$ \\
\hline $\begin{array}{l}\text { Vahedi, et al. } \\
2007 \text { DECIMAL }\end{array}$ & 38 & $\begin{array}{l}\text { Criteria: }<55 \\
\text { Range: } 22-55 \\
\text { Mean: } 43.4\end{array}$ & $\begin{array}{l}\text { Criteria: }<24 \\
\text { Range: } 7-43 \\
\text { Mean: } 20.5\end{array}$ & $\begin{array}{l}\text { At } 12 \text { months: } \\
25 \text { vs. } 78 \% \\
\text { ARR } 52.8 \% \text { in } \\
\text { surgery arm } \\
\mathbf{p}<\mathbf{0 . 0 0 0 1}\end{array}$ & $\begin{array}{l}\text { At } 12 \text { months: } \\
<3: 50 \text { vs. } 22 \% \\
\text { ( } p=0.10) \\
<4: 75 \text { vs } 22 \% \\
(p=0.0029)\end{array}$ \\
\hline $\begin{array}{l}\text { Jüttler, et al. } \\
2007 \text { DESTINY }\end{array}$ & 132 & $\begin{array}{l}\text { Criteria: 18-60 } \\
\text { Range: 29-60 } \\
\text { Mean: } 44.6\end{array}$ & $\begin{array}{l}\text { Criteria: } 12-36 \\
\text { Range and mean } \\
\text { not reported }\end{array}$ & $\begin{array}{l}\text { At } 12 \text { months: } \\
18 \text { vs. } 53 \% \\
\mathbf{p}=\mathbf{0 . 0 3}\end{array}$ & $\begin{array}{l}\text { At } 12 \text { months: } \\
<3: 47 \text { vs. } 27 \% \\
\text { ( } p=0.23) \\
<4: 77 \text { vs } 33 \% \\
(p=0.01)\end{array}$ \\
\hline $\begin{array}{l}\text { Hofmiejer, } \\
\text { et al. } 2006 \\
\text { HAMLET }\end{array}$ & 64 & $\begin{array}{l}\text { Criteria: } 18-60 \\
\text { Range: } 51-60 \\
\text { Mean: } 48.7\end{array}$ & $\begin{array}{l}\text { Criteria: }<96 \\
\text { Range: } 29-50 * \\
\text { Mean: } 41^{*}\end{array}$ & $\begin{array}{l}\text { At } 12 \text { months: } \\
22 \text { vs. } 59 \% \\
\text { ARR } 38 \% \text { in } \\
\text { surgery arm } \\
\mathbf{p}=\mathbf{0 . 0 0 2}\end{array}$ & $\begin{array}{l}\text { At } 12 \text { months: } \\
<3: \text { groups equal } \\
\text { ( } p=1.00) \\
<4: 41 \text { vs. } 59 \% \\
(p=0.13)\end{array}$ \\
\hline $\begin{array}{l}\text { Zhao, et al. } \\
2012\end{array}$ & 47 & $\begin{array}{l}\text { Criteria: } 18-80 \\
\text { Range: } 29-80 \\
\text { Median: } 64\end{array}$ & $\begin{array}{l}\text { Criteria: }<48 \\
\text { Range and mean } \\
\text { not reported }\end{array}$ & $\begin{array}{l}\text { At } 12 \text { months: } \\
16.7 \text { vs. } 69.6 \% \\
\mathbf{p}<0.001\end{array}$ & $\begin{array}{l}\text { At } 12 \text { months: } \\
<3: 25 \text { vs } 8.7 \% \\
(p=0.272) \\
<4: 75 \text { vs } 13 \% \\
\text { ( }<<0.001)\end{array}$ \\
\hline $\begin{array}{l}\text { Jüttler, et al. } 20 \\
\text { DESTINY II }\end{array}$ & 112 & $\begin{array}{l}\text { Criteria: >60 } \\
\text { Range: } 61-82 \\
\text { Median: } 70\end{array}$ & $\begin{array}{l}\text { Criteria: <48 } \\
\text { Range: } 16-50 \\
\text { Median: } 28\end{array}$ & $\begin{array}{l}\text { At } 12 \text { months: } \\
43 \text { vs } 76 \% \\
p<0.001\end{array}$ & $\begin{array}{l}\text { At } 6 \text { months: } \\
<4: 38 \text { vs } 18 \% \\
(p=0.04)\end{array}$ \\
\hline
\end{tabular}

*This was time to randomization; time to surgery is not reported.

craniectomy enlarged after aneurysm clipping in the presence of massive brain swelling, group 2 had craniectomy enlarged after aneurysm clipping in the presence of massive brain swelling with additional $\mathrm{ICH}$, group 3 had intractable ICP without radiological signs of rebleeding or infarction, group 4 had intractable ICP with signs of infarction, and group 5 had intractable ICP with rebleeding. They found that the outcome was comparable regardless of the underlying etiology leading to $\mathrm{DHC}$. The weakness of the study is the small number of patients in groups 1, 3, and 5 .

One of the challenges particular to the management of patients with $\mathrm{SAH}$ is the development of delayed cerebral ischemia. In a patient afflicted by $\mathrm{ICH}$ associated with $\mathrm{SAH}$, the timing of peak perihematomal edema formation coincides with the beginning of the development of vasospasm. Therefore a dilemma may occur in which deterioration in a patient's neurological exam is difficult to distinguish whether it is due to delayed cerebral ischemia, elevated ICP, or both. It is clear that DHC leads to effective and sustained ICP control thus helping to address this clinical dilemma. If a patient has significant improvement after DHC is performed, it can be inferred that the underlying pathophysiology was elevated ICP and not delayed cerebral ischemia. More importantly perhaps is that the treatment of elevated ICP and vasospasm use conflicting strategies. The use of hyperventilation and hyperosmolar therapy, for instance, could lead to increased vasoconstriction and dehydration respectively, both potentially worsening vasospasm. DHC in $\mathrm{SAH}$ patients allows the clinician to treat vasospasm effectively without concern for exacerbating elevated ICP from induced hypertension or hypervolemia.

Furthermore, patients with SAH may have various underlying etiologies leading to elevated ICP including ICH, infarction, rebleeding, and cerebral edema. Several studies ${ }^{10,11,13}$ suggest that the underlying etiology leading to elevated ICP could play a role in determining the effectiveness of DHC. These studies suggest that performing $\mathrm{DHC}$ for intractable ICP in the setting of an $\mathrm{ICH}$ associated with SAH is beneficial. However, Guresir et al. 15 came to a different conclusion, that the underlying etiology is not relevant in determining the usefulness of DHC. Regardless of the etiology leading to intractable ICP, there is a final common pathway of decreased cerebral perfusion which can lead to ischemia and further cerebral edema. This vicious cycle can perhaps be halted by the timely performance of DHC. Therefore, these conflicting findings could possibly be accounted for by the differences in the timing of $\mathrm{DHC}$ depending on the indication and underlying pathology. Early $\mathrm{DHC}$ versus delayed $\mathrm{DHC}$ was associated with improved functional outcome in several of these studies. ${ }^{11,13,14}$

All of the studies reviewed found that DHC can be done safely in a population of poor-grade SAH patients. Most of the studies suffer from the weaknesses inherent to a retrospective observational study and a very small sample size. Clearly, there is a need for prospective studies with standardized treatment protocols and clear indications for DHC in $\mathrm{SAH}$.

\section{DHC IN THE SETTING OF MALIGNANT MIDDLE CEREBRAL ARTERY INFARCT}

Malignant middle cerebral artery (MCA) infarct is described as a total or near total infarction of the MCA territory. ${ }^{16}$ Due to the large area of ischemia, this injury is followed by massive amounts of cerebral edema, ${ }^{17}$ peaking between days two and five. ${ }^{18}$ This progressive edema leads to herniation, resulting in death in approximately $80 \%$ of patients, even with the use of maximum medical therapy. ${ }^{16,19}$ Patients that survive are typically left severely disabled. 
The guidelines by the American Heart Association acknowledge the lack of evidence for conservative medical management in the treatment of patients with elevated ICP following stroke. ${ }^{18}$ There is poor evidence for the benefit of hyperventilation, corticosteroids, or osmotic diuretics in improving functional outcome. It is currently a Class I recommendation that patients should be monitored closely for increased ICP. Currently American Heart and American Stroke Associations' guidelines state osmotic therapy for patients with deterioration concerning for swelling is reasonable, but do not recommend hypothermia, barbiturates, or steroids given insufficient data. They also state a Class I recommendation for $\mathrm{DHC}$ in patients under the age of 60 within 48 hours. ${ }^{20}$ The Neurocritical Care Society (NCS) has similar recommendations against steroids and barbiturates, but states hypothermia may be considered in patients who are not eligible for surgery. They share the recommendation for osmotic therapy. In regards to surgery, the NCS also recommends $\mathrm{DHC}$ within $24-48$ hours, regardless of age. However, an additional recommendation is made that families of patients over 60 should consider the higher likelihood of severe disability. ${ }^{21}$ Though these guidelines acknowledge the use of DHC to acutely decrease ICP and reduce secondary injury as potentially lifesaving, the resulting functional outcome remains unclear.

In recent years, there have been a number of randomized controlled trials comparing mortality and functional outcome between patients undergoing $\mathrm{DHC}$ and patients managed with maximum medical therapy. These studies have attempted to prove not just a mortality benefit of decompression, but also improvement in functional outcome. Table 3 provides a summary of the key studies that have been published thus far.

HAMLET, DECIMAL, and DESTINY are three European trials that were published within two years of each other, and represented the first set of randomized controlled trials to compare DHC with standard medical therapy.

Jüttler et al. ${ }^{22}$ (DESTINY) published a trial evaluating 32 patients ranging in ages from 18 to 60 with symptom onset less than 36 hours prior to randomization and used a primary outcome of a modified Rankin Scale (mRS) score 0 to 3 versus 4 to 6 . The study was based on a sequential design, first evaluating 30-day mortality, and the study discontinued enrollment after 32 patients had undergone randomization and the mortality endpoint was reached. The conservative therapy group had a higher median National Institutes of Heath Stroke Scale (NIHSS) of 24 when compared to the DHC group whose median NIHSS was 21. Survival was significantly higher in the surgical group compared to the conservative therapy group at 12 months. DESTINY was limited by its small patient size, in part because the trial was terminated early given the immense survival benefit of the procedure, and in light of the simultaneously conducted trials that will be discussed below. Though the article failed to reach its primary outcome, survival benefit was decisively shown.

Vahedi et al. ${ }^{23}$ (DECIMAL) studied 38 patients aged 18-55 years who were randomized within 24 hours of symptom onset. Patients randomized to $\mathrm{DCH}$ were required to undergo the procedure within 6 hours of randomization, at most 30 hours after symptom onset. Similar to DESTINY, the primary outcome was a favorable functional outcome (mRS $\leq 3)$ at 6 months. Under the guidance of the data safety monitoring committee, enrollment was suspended early at 38 patients (18 medical, 20 surgical) due to slow patient enrollment and the intention of DECIMAL, DESTINY, and HAMLET to pool data and publish together. Again, the primary outcome of $\mathrm{mRS} \leq 3$ did not reach statistical significance.

The third European randomized controlled trial (HAMLET) was conducted by Hofmeijer et al. ${ }^{24}$ This study reported on 64 patients randomized equally between surgical and medical management. One notable difference about HAMLET is that this study randomized patients up to 4 days after initial symptom onset. The primary outcome was mRS at 1 year, with a good outcome defined as 0-3 and poor outcome of 4-6. Recruitment was stopped under the advisement of the data monitoring committee after
64 patients were enrolled because it was thought to be very unlikely that the primary outcome measure would produce a statistically significant difference. Like DECIMAL and DESTINY, HAMLET did not show a statistically significant difference between an mRS of 0 to 3 versus 4 to 6 . HAMLET, unlike DESTINY and DECIMAL did not show a significant difference when outcome was dichotomized for $m R S \leq 4(p=0.13)$.

With DESTINY, DECIMAL, and HAMLET recruiting patients simultaneously, authors from each of these studies contributed data to an article by Vahedi et al. ${ }^{25}$ This article pooled the data of the first three European trials to include patients randomized within 48 hours of symptoms onset. The article reported the data of 93 patients 18 to 60 years old. All of the patients from DESTINY and DECIMAL were included; 23 HAMLET patients were included. Overall, 51 patients received decompressive surgery, while 42 received conservative therapy. Like each of the individual studies, there was a significant benefit for $m R S>4$ cutoff and mortality at 1 year. Additionally, with the pooled data, there was a statistically significant difference between the groups for an mRS $>3$ at 12 months (medical patients $79 \%$, surgical patients $57 \%, p=0.014$ ). This study also reported that the likelihood of ending up with an mRS of 4 was 10 times greater after surgery than after standard medical therapy, but the risk of ending up with an $\mathrm{mRS}$ of 5 was not increased.

Studies then began to consider the benefits of this procedure in an older population. Zhao et al. ${ }^{26}$ had a similar study design to the European trials, but allowed patients to enroll up to 80 years of age. In patients older than 60 , risk of death was also significantly lower at 1 year. There was no statistical difference between the groups for an mRS $>3$. However, in the older subgroup, there was still a statistically significant difference when dichotomizing the groups to an $\mathrm{mRS}>4$, similar to the results with a younger patient population.

The DESTINY group conducted a second randomized controlled trial further evaluating the effect of $\mathrm{DCH}$ on older patients. ${ }^{27,28}$ Unlike the pooled analysis of the European trials, the older patient 
population was not able to achieve statistical significance when the data was dichotomized to an mRS of 0 to 3 versus 4 to 6. DESTINY II showed a survival benefit and functional benefit with data dichotomized to an mRS of $\leq 4$, though the treatment effect was diminished in the older population.

Frank et al. published HEADDFIRST, ${ }^{29}$ which randomized 26 patients within 96 hours after symptom onset. At 6 months, the DHC group had a mortality rate of $36 \%$ and $40 \%$ in the medical group which was not consistent with the previous trials. However, the randomization for HeADDFIRST required more mass effect and allowed greater delay to randomization, which the authors speculated could have led to worse outcomes. Small enrollment numbers were another methodological limitation in this study.

This discussion focuses on the major randomized controlled trials evaluating $\mathrm{DHC}$ in the management of malignant MCA infarction. Mortality benefit is significant in all studies but HeADDFIRST. However, the question of benefit in terms of functional outcome is less clear. Though the pooled European trials were able to show a benefit of surgery with an mRS of $0-3$ compared to 4-6, it also showed the increased risk of having an mRS of 4 . Whether this represents an acceptable outcome is a matter of debate and must be individualized for the patient. Even physicians have not come to a consensus as to the definition of an acceptable outcome (Neugebauer et al.), though Kiphuth et al. did find that most patients or their families would still retrospectively consent following decompression. ${ }^{30,31}$ These benefits were not reproducible using an older population, though mortality benefit and benefit with data dichotomized with an $\mathrm{mRS} \leq 4$ remained significant. More data regarding quality of life and depression following $\mathrm{DHC}$ for malignant MCA stroke would be helpful in determining the utility of this life-saving procedure.

\section{DHC IN THE SETTING OF TRAUMATIC BRAIN INJURY}

Traumatic brain injury (TBI) is an extremely prevalent problem in the United States. Approximately 2 million people each year sustain $\mathrm{TBI}$, many of whom can be treated and released from emergency departments. However, for the nearly 300,000 patients hospitalized each year, those with severe disease can have devastating outcomes, leading to thousands of deaths and patients with permanent disability. ${ }^{32}$ The reported overall mortality with medical management varies widely throughout the literature, but ranges approximately $30-40 \%{ }^{33}$

Evaluation of hemicraniectomy in nonpenetrating diffuse TBI represents a more difficult analysis than surgery following malignant MCA infarct. The initial injury prompting evaluation for surgery has more variability. The decompressions themselves can be pursued for different purposes, aiming to treat primary damage caused by lesions causing mass effect or secondary damage caused by elevated intracranial pressure. ${ }^{34,35}$

Additionally, the preferred surgical approach and timing ${ }^{35}$ of the surgery is still unclear. The pivotal study DECRA used a bifrontal approach to their craniectomy. ${ }^{36,37}$ Other studies used a bilateral hemicraniectomy approach. ${ }^{38}$ Both of these approaches fall outside of the scope of this review. The literature available is therefore limited due to the variability of the initial injury as well as the surgical approach employed.

To our knowledge, there have only been two published randomized controlled trials evaluating decompressive craniectomy in traumatic brain injury compared to maximum medical management: DECRA evaluated a bifrontal approach and yielded disappointing results, ${ }^{36}$ and a small study evaluating decompression in children showed a possible benefit. ${ }^{39} \mathrm{~A}$ third randomized controlled trial, RescuelCP, has yet to be published and will evaluate bifrontal and unilateral hemicraniectomies. ${ }^{40}$ With so few randomized controlled trials, the optimal surgical approach remains controversial for TBI.

Current guidelines for controlling ICP in $\mathrm{TBI}$ remain focused on conservative management as first line therapies: elevation of the head of the bed, pain control, sedation, ventriculostomy. When this fails to acutely manage ICP, barbiturate, hypothermia and hyperosmolar therapies have been used. ${ }^{41}$ Outcomes of patients with severe TBI managed with maximum medical therapy vary in the literature, but frequently show a mortality rate of around $40 \%$, and rates of good outcome (Glasgow Outcome Score 4-5) of 40\%. ${ }^{42}$ $\mathrm{DHC}$ is considered when these therapies fail and ICP remains elevated. DHC can rapidly decrease ICP, however, the clinical significance and outcome benefit remains unclear. ${ }^{41}$

Wen et al. ${ }^{35}$ compared early versus late $\mathrm{DHC}$, defining early $\mathrm{DHC}$ as within 24 hours of injury in $44 \mathrm{TBI}$ patients. Both groups had a 6 month mortality rate of approximately $20 \%$. However, $52 \%$ in the early DHC group achieved a GOS of $4-5$, compared to $63 \%$ in the late group, which did not reach statistical significance. Though the groups were similar, the early group had more significant midline shift. It is possible that the treatment effect is too small to be detected with such a small sample size.

Aside from the study of early versus late $\mathrm{DHC}$ in patients with TBI, there is controversy regarding whether decompression with or without evacuation of a mass lesion is more efficacious. Yuan et al. ${ }^{43}$ studied this question by examining 164 patients, 93 of whom underwent decompression with evacuation of a mass lesion at least $25 \mathrm{~mL}$ and 71 who were decompressed without evacuation of a mass lesion. About $15 \%$ more patients from the mass lesion group underwent surgery within 24 hours (72\% mass lesion, $58 \%$ diffuse edema). The mortality rate was $22 \%$ at 60 days and favored the mass lesion group ( $14 \%$ mass lesion, 32\% diffuse edema, $p=0.014$ ). Overall rate of good outcome was about $42 \%$ without a statistically significance difference between the two groups.

Aarabi et al. ${ }^{44}$ performed a similar retrospective cohort study to evaluate 50 patients with severe closed TBI, but excluded patients who had DHC with evacuation of a mass lesion. Ten patients went to surgery within the first 24 hours (9 immediately, 1 secondary to clinical worsening). The remaining 40 patients underwent DHC after 24 hours. Overall mortality was $28 \%$, and $51 \%$ of the patients had a good outcome with GOS 4-5 at 30 days. The remaining patients were left vegetative or severely disabled. 
Qiu et al. ${ }^{45}$ evaluated 74 patients with brain swelling after severe TBI and randomized patients to undergo a traditional DHC (bone window diameter $15 \mathrm{~cm}$ ) compared to the control group which underwent a unilateral temporoparietal craniectomy (bone window diameter $8 \mathrm{~cm})$. Thirty-seven patients underwent a DHC, and $57 \%$ of these patients had a GOS of 4-5 at 6 months. Additionally, $27 \%$ of the patients died, and the remaining were vegetative or severely disabled. The control group had a $57 \%$ mortality rate with only $33 \%$ achieving a good outcome. Jiang et al. ${ }^{46}$ conducted a similar study which included 486 patients. The results were similar favoring the group who underwent a traditional DHC versus a subtotal DHC.

Some of the most relevant data is from Chibbaro et al. ${ }^{47}$ This prospective study of 147 patients evaluated DHC following TBI. Of these patients, $67 \%$ had a GOS 4-5 at a mean follow up of 26 months. GOS was $2-3$ in $19 \%$ of patients, and mortality rate was just $14 \%$. Subgroup analysis was performed to determine factors associated with improved outcome. Good outcomes were significantly associated with age less than 50 $(p<0.0001)$ and operation within 9 hours of trauma $(p<0.03)$.

Throughout the literature, good outcome rates vary from $30-50 \%$ in the $\mathrm{DHC}$ group, with a mortality rate approximately $20 \%{ }^{48,49} \mathrm{DHC}$ remains a controversial option in the management of patients following TBI. The surgery may decrease mortality, and it appears, similar to other studies evaluating DHC for other indications, that timing plays a significant role. However, studies in the form of randomized controlled trials comparing $\mathrm{DHC}$ to maximal medical management are needed. Unfortunately, there remain a number of barriers to studies of this kind. The heterogeneity of TBI patients will be a constant challenge. Mechanism of injury, the presence or absence of a mass lesion, and the possible presence of other injury remain challenges for patient randomization and data interpretation. Additionally, researchers continue to disagree about the surgery's timing (early versus late), use for mass lesions versus diffuse edema, and even the preferred surgical approach.

\section{CONCLUSIONS}

In this review, we describe the current evidence regarding the utility of $\mathrm{DHC}$ for the management of elevated ICP due to malignant MCA stroke, ICH, TBI, and SAH. All of these disease processes share a common pathophysiologic endpoint of elevated ICP that can be refractory to maximal medical therapy and lead to herniation syndromes. It appears that $\mathrm{DHC}$ can be safely performed with minimal risk in these critically ill patients. Furthermore, it appears that the earlier $\mathrm{DHC}$ is performed the greater the potential benefit. While DHC may be a life-saving procedure, the patients are nevertheless often left significantly impaired. Therefore, it is imperative to discuss the potential outcomes that are possible with the patient or surrogate decision maker. The issue of prognostication of outcome in severe brain injury is beyond the scope of this paper, but it is clear that in all of the disease processes reviewed that a potential exists for a good functional recovery. Therefore, DHC should be part of the armamentarium in the management of elevated ICP in the conditions discussed. Ultimately, the decision to pursue $\mathrm{DHC}$ should be individualized taking into consideration the patient's values and goals of care.

\section{REFERENCES}

1. Morgenstern, L.B., et al., Guidelines for the management of spontaneous intracerebral hemorrhage: a guideline for healthcare professionals from the American Heart Association/American Stroke Association. Stroke, 2010. 41(9): p. 2108-29.

2. Takeuchi, S., et al., Ventriculomegaly after decompressive craniectomy with hematoma evacuation for large hemispheric hypertensive intracerebral hemorrhage. Clin Neurol Neurosurg, 2013. 115(3): p. 317-22.

3. Shimamura, N., et al., Decompressive hemicraniectomy is not necessary to rescue supratentorial hypertensive intracerebral hemorrhage patients: consecutive singlecenter experience. Acta Neurochir Suppl, 2011. 111: p. 415-9.

4. Ramnarayan, R., et al., Decompressive hemicraniectomy in large putaminal hematomas: an Indian experience. J Stroke Cerebrovasc

5. Murthy, J.M., et al., Decompressive craniectomy with clot evacuation in large hemispheric hypertensive intracerebral hemorrhage. Neurocrit Care, 2005. 2(3): p. 258-62.
6. Ma, L., et al., Decompressive craniectomy in addition to hematoma evacuation improves mortality of patients with spontaneous basal ganglia hemorrhage. J Stroke Cerebrovasc Dis, 2010. 19(4): p. 294-8.

7. Kim, K.T., et al., Comparison of the effect of decompressive craniectomy on different neurosurgical diseases. Acta Neurochir (Wien), 2009. 151(1): p. 21-30.

8. Fung, C., et al., Decompressive hemicraniectomy in patients with supratentorial intracerebral hemorrhage. Stroke, 2012. 43(12): p. 3207-11.

9. Dierssen, G., R. Carda, and J.M. Coca, The influence of large decompressive craniectomy on the outcome of surgical treatment in spontaneous intracerebral haematomas. Acta Neurochir (Wien), 1983. 69(1-2): p. 53-60.

10. Dorfer, C., et al., Decompressive hemicraniectomy after aneurysmal subarachnoid hemorrhage. World Neurosurg, 2010. 74(4-5): p. $465-71$.

11. Buschmann, U., et al., Decompressive hemicraniectomy in patients with subarachnoid hemorrhage and intractable intracranial hypertension. Acta Neurochir (Wien), 2007. 149(1): p. 59-65.

12. D'Ambrosio, A.L., et al., Decompressive hemicraniectomy for poor-grade aneurysmal subarachnoid hemorrhage patients with associated intracerebral hemorrhage: clinical outcome and quality of life assessment. Neurosurgery, 2005. 56(1): p. 12-9; dicussion 19-20.

13. Smith, E.R., B.S. Carter, and C.S. Ogilvy, Proposed use of prophylactic decompressive craniectomy in poor-grade aneurysmal subarachnoid hemorrhage patients presenting with associated large sylvian hematomas. Neurosurgery, 2002. 51(1): p. 117-24; discussion 124.

14. Schirmer, C.M., D.A. Hoit, and A.M. Malek, Decompressive hemicraniectomy for the treatment of intractable intracranial hypertension after aneurysmal subarachnoid hemorrhage. Stroke, 2007. 38(3): p. 987-92.

15. Guresir, E., et al., Decompressive hemicraniectomy in subarachnoid haemorrhage: the influence of infarction, haemorrhage and brain swelling. J Neurol Neurosurg Psychiatry, 2009. 80(7): p. 799-801.

16. Berrouschot, J., et al., Mortality of spaceoccupying ('malignant') middle cerebral artery infarction under conservative intensive care. Intensive Care Med, 1998. 24(6): p. 620-3.

17. Wijdicks, E.F. and M.N. Diringer, Middle cerebral artery territory infarction and early brain swelling: progression and effect of age on outcome. Mayo Clin Proc, 1998. 73(9): p. 829-36. 
18. Adams, H.P., Jr., et al., Guidelines for the early management of adults with ischemic stroke: a guideline from the American Heart Association/American Stroke Association Stroke Council, Clinical Cardiology Council, Cardiovascular Radiology and Intervention Council, and the Atherosclerotic Peripheral Vascular Disease and Quality of Care Outcomes in Research Interdisciplinary Working Groups: The American Academy of Neurology affirms the value of this guideline as an educational tool for neurologists. Circulation, 2007. 115(20): p. e478-534

19. Hacke, W., et al., 'Malignant' middle cerebral artery territory infarction: clinical course and prognostic signs. Arch Neurol, 1996. 53(4): p 309-15.

20. Wijdicks, E.F., et al., Recommendations for the management of cerebral and cerebellar infarction with swelling: a statement for healthcare professionals from the American Heart Association/American Stroke Association. Stroke, 2014. 45(4): p. 1222-38.

21. Torbey, M.T., et al., Evidence-Based Guidelines for the Management of Large Hemispheric Infarction: A Statement for Health Care Professionals from the Neurocritical Care Society and the German Society for NeuroIntensive Care and Emergency Medicine. Neurocrit Care, 2015

22. Juttler, E., et al., Decompressive Surgery for the Treatment of Malignant Infarction of the Middle Cerebral Artery (DESTINY): a randomized, controlled trial. Stroke, 2007. 38(9): p. 2518-25.

23. Vahedi, K., et al., Sequential-design, multicenter, randomized, controlled trial of early decompressive craniectomy in malignant middle cerebral artery infarction (DECIMAL Trial). Stroke, 2007. 38(9): p. 2506-17.

24. Hofmeijer, J., et al., Surgical decompression for space-occupying cerebral infarction (the Hemicraniectomy After Middle Cerebral Artery infarction with Life-threatening Edema Trial [HAMLET]): a multicentre, open, randomised trial. Lancet Neurol, 2009. 8(4): p. 326-33.

25. Vahedi, K., et al., Early decompressive surgery in malignant infarction of the middle cerebral artery: a pooled analysis of three randomised controlled trials. Lancet Neurol, 2007. 6(3): p. 215-22

26. Zhao, J., et al., Decompressive hemicraniectomy in malignant middle cerebral artery infarct: a randomized controlled trial enrolling patients up to 80 years old. Neurocrit Care, 2012. 17(2): p. 161-71.

27. Juttler, E., et al., DESTINY II: DEcompressive Surgery for the Treatment of malignant INfarction of the middle cerebral arterY II. Int J Stroke, 2011. 6(1): p. 79-86.

28. Juttler, E., et al., Hemicraniectomy in older patients with extensive middle-cerebral-artery stroke. N Engl J Med, 2014. 370(12): p. 1091100.
29. Frank, J.I., et al., Hemicraniectomy and durotomy upon deterioration from infarctionrelated swelling trial: randomized pilot clinical trial. Stroke, 2014. 45(3): p. 781-7.

30. Neugebauer, $\mathrm{H}$., et al., DESTINY-S: attitudes of physicians toward disability and treatment in malignant MCA infarction. Neurocrit Care, 2014. 21(1): p. 27-34

31. Kiphuth, I.C., et al., Hemicraniectomy for malignant middle cerebral artery infarction: retrospective consent to decompressive surgery depends on functional long-term outcome. Neurocrit Care, 2010. 13(3): p. 380-4.

32. Faul, M.D., et al., Traumatic brain injury in the United States; emergency department visits, hospitalizations, and deaths. CDC Stacks, 2010

33. Steyerberg, E.W., et al., Predicting outcome after traumatic brain injury: development and international validation of prognostic scores based on admission characteristics. PLOS Med, 2008. 5(8): p. e165; discussion e165.

34. Al-Jishi, A., et al., Primary or secondary decompressive craniectomy: different indication and outcome. Can J Neurol Sci, 2011. 38(4): p. 612-20.

35. Wen, L., et al., A prospective study of early versus late craniectomy after traumatic brain injury. Brain Inj, 2011. 25(13-14): p. 1318-24.

36. Cooper, D.J., et al., Decompressive craniectomy in diffuse traumatic brain injury. N Engl J Med, 2011. 364(16): p. 1493-502.

37. Cooper, D.J., et al., Early decompressive craniectomy for patients with severe traumatic brain injury and refractory intracranial hypertension--a pilot randomized trial. J Crit Care, 2008. 23(3): p. 387-93.

38. Walcott, B.P., et al., Bilateral hemicraniectomy in non-penetrating traumatic brain injury. $J$ Neurotrauma, 2012. 29(10): p. 1879-85.

39. Taylor, A., et al., A randomized trial of very early decompressive craniectomy in children with traumatic brain injury and sustained intracranial hypertension. Childs Nerv Syst, 2001. 17(3): p. 154-62.

40. Hutchinson, P.J., et al., Decompressive craniectomy in traumatic brain injury: the random ized multicenter RESCUEicp study (http:// www.RESCUEicp.com). Acta Neurochir Suppl 2006. 96: p. 17-20

41. Brain Trauma, F., et al., Guidelines for the management of severe traumatic brain injury. VI. Indications for intracranial pressure monitoring. J Neurotrauma, 2007. 24 Suppl 1: p. S37-44.

42. Chesnut, R.M., et al., A trial of intracranialpressure monitoring in traumatic brain injury. N Engl J Med, 2012. 367(26): p. 2471-81.

43. Yuan, Q., et al., Comparative study of decom pressive craniectomy in traumatic brain injury with or without mass lesion. Br J Neurosurg. 2013. 27(4): p. 483-8
44. Aarabi, B., et al., Outcome following decom pressive craniectomy for malignant swelling due to severe head injury. J Neurosurg, 2006. 104(4): p. 469-79.

45. Qiu, W., et al., Effects of unilateral decompressive craniectomy on patients with unilateral acute post-traumatic brain swelling after severe traumatic brain injury. Crit Care, 2009. 13(6): p. R185

46. Jiang, J.Y., et al., Efficacy of standard trauma craniectomy for refractory intracranial hypertension with severe traumatic brain injury: a multicenter, prospective, randomized controlled study. J Neurotrauma, 2005. 22(6): p. 623-8

47. Chibbaro, S., et al., Decompressive craniectomy and early cranioplasty for the management of severe head injury: a prospective multicenter study on 147 patients. World Neurosurg, 2011. 75(3-4): p. 558-62.

48. Aarabi, B., et al., Comparative study of decompressive craniectomy after mass lesion evacuation in severe head injury. Neurosurgery, 2009. 64(5): p. 927-39; discussion 939-40.

49. Bohman, L.E. and J.M. Schuster, Decompressive craniectomy for management of traumatic brain injury: an update. Curr Neurol Neurosci Rep, 2013. 13(11): p. 392.

\section{Corresponding Author}

\section{Barak Bar, MD}

Assistant Professor

Department of Neurological Surgery

Thomas Jefferson University Hospital

909 Walnut St, 3rd Floor

Philadelphia, PA 19107

P: 215-503-5550

E: Barak.Barajefferson.edu 